\title{
NOTA
}

\section{ETEA cumple 50 años}

\section{José Juan Romero Rodríguez S. I. y Adolfo Rodero Franganillo}

Resumen: Esta nota presenta sintéticamente la historia de la institución cordobesa ETEA con ocasión de su cincuentenario (1963-2013) y, a partir de ella, una breve consideración de su misión educativa universitaria y social, a la que caracteriza como "misión de alcance", subrayando especialmente dos aspectos: la investigación agraria y la comunidad humana universitaria que ha existido en la institución en este período.

Palabras clave: Compañía de Jesús, empresarios agrarios, ETEA, investigación agraria, misión universitaria.

Fecha de recepción: 17 de octubre de 2013.

Fecha de admisión definitiva: 21 de noviembre de 2013.

\section{Introducción}

En primer lugar, agradecemos la deferencia de la Revista de Fomento Social por invitarnos a aportar nuestras breves reflexiones con motivo del 50 aniversario del nacimiento de ETEA. Otros compañeros y colegas podrían haberlo hecho con tanta o mayor razón y con más competencia.

\footnotetext{
1 Profesores eméritos de la Facultad de Ciencias Económicas y Empresariales - ETEA de Córdoba.
} 


\section{ETEA turns 50}

Abstract: This note presents synthetically the history of institution ETEA (Córdoba) on the occasion of its fiftieth anniversary (1963-2013) and, from it, a brief consideration of its educational and social mission, to which characterizes as "outreach mission", emphasizing especially two aspects: agricultural research and the University human community that has existed in the institution in this period.

Key words: Society of Jesus, agricultural entrepreneurs, ETEA, agricultural research, University mission.

\section{ETEA 50 ans}

Résumé: Cette note présente synthétiquement l'histoire de l'ETEA, institution universitaire de Cordoue, à l'occasion de son cinquantième anniversaire (1963-2013) ainsi qu'un bref examen de sa mission éducative universitaire et social, "mission de portée", soulignant notamment deux aspects : la recherche agricole et la communauté humaine universitaire qui a existé dans l'institution au cours de cette période.

Mots clefs: Compagnie de Jésus, entrepreneurs agricoles, ETEA, recherche agricole, mission de l'Université

Lo hacemos mirando hacia atrás, como no podía ser de otro modo, pero también con la mirada puesta en el nuevo horizonte que representa la puesta en marcha de la Universidad Loyola Andalucía

No hay que ser muy perspicaces para adivinar que el motivo para solicitarnos esta colaboración tiene que ver con nuestra condición de miembros del Consejo de Redacción de la Revista desde su traslado a ETEA en 1991 y de "veteranos históricos" de esta querida institución. Ello tiene sus ventajas y sus inconvenientes. Ventaja, sin duda, el hecho de que hemos recorrido casi toda la andadura de ETEA en esas 5 décadas, lo que nos permite disponer de una visión bastante completa de su historia, y también que, en su tanto, hemos sido protagonistas de la misma.

Precisamente esta última ventaja se puede convertir en un inconveniente, ya que nos cuesta sin duda ser objetivos en nuestras valoraciones; por otro lado, la posibilidad de tener una perspectiva de largo plazo puede representar también un inconveniente por la tendencia natural de las personas mayores a pensar que todo tiempo pasado fue mejor; otro inconveniente puede ser la falta de imparcialidad por nuestra condición de protagonistas activos de esa misma historia. Confiamos no caer demasiado en esas trampas.

Permítannos los lectores confesar que, a lo largo de estos $40-45$ años, hemos sido felices en nuestro trabajo. Hemos dedicado toda nuestra vida laboral a un proyecto que merecía la pena. No todo el mundo puede decir lo mismo del suyo... 


\section{Un poco de historia ${ }^{2}$}

La Escuela Superior de Técnica Empresarial Agrícola (ETEA) comenzó su actividad el 2 de octubre de 1963, en el claustro de la Real Colegiata de San Hipólito de Córdoba. En 1965, se trasladó a un edificio nuevo ubicado en el Parque Cruz Conde, que sería completado con otros tres en las décadas siguientes hasta constituir el actual campus cordobés de la Universidad Loyola Andalucía. Su creación fue el resultado de tres circunstancias convergentes. A finales de la década de 1950 se estaba produciendo en España el paso de la llamada agricultura tradicional a la agricultura empresarial con la intensificación de los regadíos, la mecanización agraria, y la asunción por las empresas agrarias de técnicas modernas de gestión empresarial. En segundo lugar, un grupo de jóvenes jesuitas que estaba finalizando los estudios de Teología concibieron la puesta en marcha de una institución de estudio e investigación sobre la problemática social y económica de Andalucía. Finalmente D. Lorenzo López Cubero hizo un ofrecimiento a la Compañía de Jesús de crear una institución educativa y social al servicio del desarrollo del mundo agrario de Andalucía, en memoria de su hijo Rafael Luis, fallecido; con este motivo la Fundación Rafael Luis López Jiménez, promovida por su familia, financió la compra del solar y la construcción del edificio, ya citado. Estas tres circunstancias convergieron en la fundación de ETEA en Córdoba.

Inicialmente, ETEA fue reconocido como Centro privado de Formación Profesional con categoría de estudios universitarios ${ }^{3}$. En ese mismo tiempo, cuando todavía no se habían establecido en la Universidad española las Ciencias Empresariales (la primera Facultad se creó por la Universidad de Sevilla en 1971), la Compañía de Jesús había ido creando en España diversos centros de enseñanza superior en ciencias empresariales, tales como ESTE en San Sebastián (1956), ICADE en Madrid (1958), ESADE en Barcelona (1959), INEA en Valladolid (1964) y ESCE en Alicante (1965, extinguida en 1982), siguiendo el surco abierto por la Universidad Comercial de Deusto en Bilbao (1916).

\footnotetext{
2 Para más detalles, cfr. LORING MIRÓ, J.: "Orígenes, historia y valores de ETEA, una institución universitaria de la Compañía de Jesús". Lección inaugural del curso 2012-2013. En Revista de Fomento Social, n 267, vol. 67, julio-septiembre 2012, pp. 367-389. Jaime Loring SJ lideró el equipo fundador de ETEA y fue su director de 1963 a 1970 y de 1980 a 1989. Además, han dirigido la institución los profesores: Vicente Theotonio Cáceres SJ (q.e.p.d.), Adolfo Rodero Franganillo, Manuel Cabanes Fuentes, Jesús Ramírez Sobrino y Gabriel Ma Pérez Alcalá, actual rector de la Universidad Loyola Andalucía. Véase también nuestro prólogo de la publicación: SÁNCHEz-BAYÓN, A. (coord.): Innovación docente en los nuevos estudios universitarios: teorías y métodos para la mejora permanente y un adecuado uso de las TIC en el aula (Valencia: Tirant Lo Blanch/Universidad Loyola Andalucía). En prensa.
}

${ }^{3}$ Orden Ministerial de 1 de diciembre de 1964. BOE 16-12-1964, n 301, pg. 16.796. 
Es significativo que el informe del Banco Internacional de Reconstrucción y Fomento (BIRD) y de la FAO con el título de "El desarrollo de la Agricultura en España", publicado en 1966 por el Ministerio de Hacienda, recomendara al Gobierno español el modelo de estudios cursados en ETEA.

En 1978 ETEA fue transformada en Colegio Universitario de Ciencias Empresariales adscrito a la Universidad de Córdoba ${ }^{4}$, en parte por la conveniencia de conseguir el reconocimiento del título; una consecuencia de este cambio fue que el Centro no se limitó a partir de entonces a la especialidad agraria. Ello dio validez al primer ciclo de la licenciatura; el segundo ciclo tuvo también reconocimiento mediante un acuerdo con la Universidad Comillas. En 1983 se crea en ETEA la Escuela Universitaria de Estudios Empresariales adscrita a la Universidad de Córdoba 5 . En 1988 se autoriza la transformación del colegio universitario de Córdoba en Facultad de Ciencias Económicas y Empresariales adscrita a la Universidad de Córdoba ${ }^{6}$. A finales de los 80 comienzan a impartirse estudios de doctorado; la primera tesis doctoral propia fue sostenida en ETEA en 1994. En 1996 se comenzó a impartir la Licenciatura en Investigación y Técnicas de Mercado. En los últimos años, se han modificado los grados siguiendo la nueva normativa emanada de la creación del Espacio Europeo de Educación Superior. El último importante jalón de esta historia es el reconocimiento por ley del Parlamento de Andalucía ${ }^{7}$ de la Universidad Loyola Andalucía el 23 de noviembre de 2011.

La historia de la Institución ha sido, pues, una constante adaptación a las condiciones cambiantes del entorno. En su nivel universitario, esta adaptación se ha realizado optando por un modelo de institución universitaria de iniciativa social, concebida con una clara vocación de servicio público.

\footnotetext{
${ }^{4}$ Real Decreto 2348/1978 de 15 de septiembre de 1978. BOE 3-10-1978, n² 236, pg. 22.993.

${ }^{5}$ Decreto 1059/1983 de 9 de marzo de 1983. BOE, 30-04-1983, n 103, págs. 12.072-12.073.

${ }^{6}$ Decreto 254/1988 de la Junta de Andalucía de 12 de julio. BOJA, n 71, de 13-09-1988, pg. 3.971 .

7 Ley $12 / 2011$, de 16 de diciembre, de modificación de la ley andaluza de universidades. BOJA, $\mathrm{n}^{\circ}$ 251 de 27/12/2011. Disposición adicional primera.
} 


\section{Una misión "de alcance"}

La historia de ETEA es mucho más que una sucesión cronológica de hechos, de acontecimientos, de personas. Constituye un auténtico "relato" en el sentido moderno, cargado de argumento, de sentido, de líneas de fuerza.

Conviene poner de manifiesto cuál ha sido el proyecto universitario de ETEA, su horizonte.

Ya en los Estatutos de 1964 (art ${ }^{\circ}$ 5) se definía de esta manera:

"Colaborar con una mentalidad cristiana a buscar y promover soluciones dinámicas del problema agrario en sus aspectos religioso, social, jurídico, estructural y económico"

Y, en consonancia con las nuevas formulaciones post-Concilio Vaticano II de la Compañía de Jesús, la misión quedó así explicitada en los artículos 6 a 8 de los Estatutos de la Institución de 1991:

Art. 6.- INSA-ETEA es un medio adecuado para la realización de la misión de la Compañía de Jesús, tal como hoy la concibe: el servicio de la fe y la promoción de la justicia, lo que implica una opción preferencial por los pobres.

Art. 7.- INSA-ETEA pretende que este servicio de la fe y promoción de la justicia sea el factor integrador de todas las personas que trabajan en la misma, si bien desde el respeto a la libertad de conciencia personal.

Art. 8.- En este marco INSA-ETEA tiene como objetivo servir de cauce institucional para la aplicación de la ética cristiana al ámbito de las ciencias económicas y sociales, con carácter prioritario. Se mantendrá una especial atención al sector agrario.

Estas formulaciones han sido reactualizadas en la última versión del proyecto corporativo de UNIJES ${ }^{8}$, que es la red de centros universitarios de la Compañía de Jesús en España?.

\footnotetext{
8 UNIJES Está formada hoy por las siguientes instituciones, con indicación del año de fundación: Universidad de Deusto. Bilbao - San Sebastián. 1886. Universidad Pontificia Comillas. Madrid. 1890. IQS (Instituto Químico de Sarriá). Barcelona. 1916. ESADE. Barcelona. 1958. IQS y ESADE forman parte de la Universidad Raimundo Lulio. Universidad Loyola Andalucía Córdoba/Sevilla, 1963/201 1 . INEA (Escuela Universitaria de Ingeniería Técnica Agrícola). Valladolid. 1964. CESTE (Centro de Estudios Superiores Técnico-Empresariales). Santander. 1965. Escuela Universitaria de Magisterio -Sagrada Familia (SAFA). 1949. Facultad de Teología. Granada. 1939. ITF (Institut de Teología Fonamental) San Cugat del Vallés. 1991. TSI- Turismo Sant Ignasi. Barcelona. 1997.

9 "La misión de UNIJES es la misión intelectual-universitaria de la Compañía de Jesús. Para ello se necesitan personas y comunidades universitarias:
} 


\section{A modo de balance}

Entrando en el contenido material de su actividad, ETEA ha sido, ante todo, un centro de alta calidad docente. Su carácter de institución privada, financiada casi exclusivamente por las tasas académicas del alumnado, sin ningún tipo de subvención oficial (ni para la docencia ni para la investigación) justifica que hayamos destacado más en la vertiente de la calidad del proceso de docencia-aprendizaje. La actividad docente se ha cumplido siempre a rajatabla (calendarios y horarios, regularidad de las clases, etc.); se ha atendido al alumnado de forma personal; y se ha procurado en todo momento que la "filosofía" del Centro apareciera, no solo en el plan de estudios, sino también en el comportamiento de todo el personal. La valoración de los antiguos alumnos y las muestras de aprecio demuestran que no se ha "mimado" al alumnado, pero sí se le ha respetado. En el terreno profesional, los resultados son muy apreciables: numerosos antiguos alumnos y alumnas ocupan altos cargos en empresas e instituciones; un número significativo de titulados desarrollan tareas cualificadas de cooperación al desarrollo etc. Este ha sido históricamente un aspecto estructural común a prácticamente todos los centros universitarios de la red española jesuita UNIJES.

No obstante, ha sido mucha y buena la investigación hecha en ETEA. Habría que detenerse en la larga relación de trabajos de todo tipo relacionados con las políticas agrarias, el desarrollo rural, la economía social, la responsabilidad social empresarial, las finanzas, la ética, los métodos cuantitativos, pobreza y cooperación al desarrollo etc. sin contar las numerosas investigación en las áreas tradicionalmente

- ajenas a falsas seguridades culturales pero también al escepticismo, con una visión interdisciplinar;

- abiertas a las distintas antropologías, saberes e inspiraciones que conviven en la cultura global actual;

- que asuman los retos de relacionar la fe con la justicia y la cultura en nuestra Europa secularizada, globalizada y rica;

- que perciban, en los diversos contextos una llamada al sentido crítico, a la creatividad y al compromiso;

- que posibiliten la apertura a Dios y la presencia de la sabiduría cristiana.

Esta misión se desarrolla en tres ámbitos:

- En relación con los estudiantes: facilitando la formación de personas conscientes, competentes, compasivas, comprometidas, abiertas a la pregunta sobre el sentido y capaces de percibir las preguntas y vivencias del cristianismo.

- En la aportación del conocimiento: mediante la elaboración de saberes, con rigor científico y calidad académica, desde un compromiso solidario con los menos favorecidos.

- En la presencia en la sociedad: incidencia social, con calidad y capacidad de diálogo desde nuestra identidad cristiana específica". 
"empresariales" (finanzas, organización, recursos humanos, marketing etc.). Casi siempre con financiación no oficial. Durante décadas nuestro claustro docente ha enriquecido de forma considerable la nómina de tesis doctorales propias y dirigido las de otras muchas personas. Es una historia que está muy documentada y que no es el momento de recordar aquí con detalle. En los últimos años, se han multiplicado los esfuerzos por fortalecer el tipo de investigación que hoy se requiere, en particular para acceder a publicaciones de prestigio, con resultados alentadores.

No hay espacio para detallar la referencia a su influjo en el sector agrario (origen del Centro, que se mantiene como una línea prioritaria de investigación), regional (participando activamente a lo largo de toda su historia en numerosas iniciativas de investigación y formulación de políticas a escala de Andalucía) y nacional (habría que recordar, por ejemplo, su rol histórico en el fortalecimiento de la red jesuita UNIJES y de su precedente la FLECE) y a sus múltiples lazos académicos, científicos etc. con otras instituciones universitarias internacionales. Vamos a fijarnos brevemente en un aspecto ya citado del impacto social de ETEA: el de su proyección internacional en el ámbito de la cooperación al desarrollo. En efecto, ha sido sobre todo notable la proyección de nuestra institución para cooperar con países en vías de desarrollo, principalmente en Centroamérica.

Aunque hay algunos precedentes, sobre todo desde 1986 se han venido desarrollando numerosas iniciativas académicas y de proyectos sobre el terreno que, a partir de 2002, quedaron insertas en el marco de la nuevo Fundación ETEA para el Desarrollo y la Cooperación. Es esta una línea de fuerza de ETEA, tanto desde el punto de vista estrictamente científico (investigaciones, tesis doctorales), como en la docencia (cursos de posgrado, máster en Cooperación etc.), como de trabajo en terreno (proyectos de desarrollo, formulación de políticas etc.). En esta área, se puede decir que ETEA "ha creado escuela"; hemos contribuido a formar muchas personas que han trabajado en cooperación tanto en la base como en puestos de responsabilidad; en el mundo de la cooperación al desarrollo somos una entidad de referencia, sobre todo en Centroamérica, y otros países latinoamericanos, pero también en otros ámbitos geográficos (Asia del sureste en particular, comenzando por Vietnam y siguiendo por Camboya, Bangla Desh y Timor Este).

Uno de los frutos más valiosos en este ámbito es la creación y consolidación de unos especiales lazos de amistad y estrecha y leal colaboración con las tres universidades centroamericanas confiadas a la Compañía de Jesús. No siempre ha sido fácil, pero nuestra vivencia histórica al respecto es sumamente gratificante. 


\section{Un gran grupo humano}

En estos 50 años, ETEA ha sido, ante todo, su gente. Hemos trabajado, codo con codo, jesuitas y laicos, compañeros y compañeras docentes y no docentes, como una familia. El alumnado ha sido el foco de nuestra atención, haciendo realidad el principio pedagógico del paradigma jesuita: la cura personalis. Juntos hemos gozado y sufrido; ha sido el trabajo común y solidario quien nos ha hecho llegar hasta donde estamos, porque nunca nadie nos ha regalado nada. En cualquier caso, una de nuestras vivencias más gratificantes es la conciencia de formar parte de un colectivo excepcional, diverso y plural, formado por personas honestas y leales, con unos intereses y una dedicación que desbordan ampliamente el mero cumplimiento de las obligaciones contractuales. ETEA no hubiera sido viable sin el esfuerzo y la dedicación generosa, sacrificada, en algunos casos casi excesiva, de esas personas. Ellas constituyen su patrimonio más valioso, su activo más cargado de oportunidades de crecimiento institucional. Conviene recordarlo ahora que se inicia la nueva e ilusionante etapa de la Universidad Loyola Andalucía.

No ha sido un proceso idílico, ni han faltado tensiones y conflictos (dentro y fuera) que siempre hemos sido capaces de superar entre todos. Ha habido problemas económico-financieros; también los importantes cambios de marco político han condicionado la estructura del Centro; sin olvidar la lenta, muy lenta, aceptación de ETEA por la propia sociedad cordobesa. Por el contrario, los aspectos positivos son muy numerosos; además de los ya citados, hay que subrayar el apoyo de la Compañía de Jesús que ha ido siempre unido al respeto absoluto de la autonomía del Centro. Pero, como hoy se dice, la "resiliencia" ha sido una de nuestras características diferenciales: hemos sido capaces de superar una serie de retos institucionales, de vencer obstáculos que parecían insalvables, de salvar situaciones aparentemente insuperables.

Es, por eso, connatural a esta historia la transformación de ETEA en la nueva Universidad Loyola Andalucía, ampliando de forma considerable su abanico de titulaciones e inaugurando su presencia académica en Sevilla: no es más que su desenlace natural. La Universidad Loyola Andalucía no es sino el fruto maduro de esta historia de 50 años de servicio universitario. Por decirlo gráficamente, hace ya muchos años que "el traje de centro adscrito" se había quedado pequeño dado el contexto geográfico, social y cultural en que nos movemos y teniendo en cuenta el espléndido y maduro colectivo de personal docente y de administración y servicios. La Universidad Loyola Andalucía - a pesar de la dificultad intrínseca del proyecto y del complicado contexto externo en que nace- es una aventura 
ilusionante y cargada de promesas. Con una clara misión: hacer más efectiva y dar mayor alcance a la misión universitaria de inspiración jesuita.

Ojalá esta naciente Universidad Loyola, prolongación y culminación de la aventura de ETEA, sea fiel al espíritu que nos hemos atrevido a sintetizar como el "espíritu de ETEA", adaptándose al nuevo contexto mundial y a sus nuevos ámbitos geográfico, institucional y académico. 